\title{
Optimize the Strength and Size of Preformed Particle Gels for Better Conformance Control Treatment
}

\section{Abdulmohsin Imqam, Baojun Bai*, Missouri University of Science and Technology}

*tel:(573)-341-4016/email address: baib@mst.edu

\section{Abstract}

A newer trend in gel treatments is using preformed particle gel (PPG) to reduce fluid channels through super-high permeability streaks/fractures and thus to decrease water production and increase sweep efficiency for mature oilfields. The success of a PPG treatment mainly depends on whether or not the PPG can effectively reduce the permeability of the channels to an appropriate level. This work sought to determine what factors significantly influence the blocking efficiency of PPG in fluid channels. A transparent filtration model was designed to observe the compression of gel particles in fluid channels at several differential pressures and to study the effect of various parameters, such as brine concentrations and particle sizes, on PPG blocking efficiency. The results suggested that rather than fully blocking the channel, a permeable gel pack was formed in the fluid channel by gel particles, and its permeability was dependent on the gel strength, particle size, and load pressure. The gel pack permeability decreased as the gel strength, particle size, and load pressure increased. Thus, the blocking efficiency of the particle gel on a channel is increased if large sizes or/and strong particles are used. The gel pack permeability was a few hundred millidarcies before the load pressure was applied; it decreased to less than $10 \mathrm{md}$ when the load pressure rose. The results also indicated that the PPG pack was compressible and its compressibility decreased as the load pressure increased. These results can be effectively used to optimize a PPG design. A gel pack that has a desired permeability can be devised by selecting the proper gel strength and particle size corresponding to the reservoir pressure. This is essential for a successful gel treatment so as to reduce the permeability to a manageable preplanned degree.

\section{Keywords}

Preformed particle gel, Fluid channel, Gel treatment, Water management, Conformance control

\section{Introduction}

Water production from hydrocarbon reservoirs causes major problems worldwide as more reservoirs become mature. Excess water production triggers a higher level of corrosion and scales, an increased load on fluid handling facilities, additional environmental concerns, and the shorter economic life of a well. Various materials have been proposed to reduce both water channeling and high water cuts to enhance the oil recovery of mature oilfields. Gel treatment has been widely applied as a cost-effective method to reduce excess water production; it can improve the macroscopic sweep efficiency by plugging high permeability zones during hydrocarbon production. Different gel types have been used to control water production through either high permeability channels or fractures without damaging highly oil-saturated unswept zones. Traditionally, in situ bulk gels are used for conformance control. They consist of a mixture of polymer and crosslinker 
(gallant) injected either together or separately with a slug. A crosslinking reaction then occurs by using a specific trigger to generate gels in situ at reservoir temperature to either fully or partially plug the formation. This technology, however, has several disadvantages that restrict its applications for conventional reservoirs, such as a lack of gelation time control, gelling uncertainty due to shear degradation, chromatographic separation between polymer and crosslinker, and dilution by the formation of water and minerals (Chauveteau et al., 1999, 2001, 2003; Coste et al. 2000; Bai et al., 2007a, 2007b). In recent years, newer gel systems have been developed to overcome these drawbacks. These newer gels have a better performance because they are formed at surface facilities and then injected into target zones with no need for gelation to occur under reservoir conditions. These gels have different commercial product names, and they include PPGs, microgels, temperature sensitive polymer microgels, and $\mathrm{pH}$ sensitive polymer microgels. PPGs are superabsorbent crosslinking polymers that can swell up to 200 times their original size in brine. A PPG is a millimeter-size particle formed at the surface. It is then dried and crushed into small particles to inject into a reservoir (Coste et al., 2000; Bai et al, 2007a, 2007b). Microgels are injected into a reservoir as fully water soluble, nontoxic, soft, stable, and size-controlled. They have particle sizes between 10 and 1000 nm (Chauveteau et al., 1999, 2001, 2003; Rousseau et al., 2005; Zaitoun et al., 2007). Temperature sensitive polymer microgels (BrightWater ${ }^{\circledR}$ ) are submicron gel particles. They are injected into the reservoir with cooler injection water relative to the reservoir temperature. As the polymer passes through the reservoir, it gradually picks up heat from the surrounding warmer reservoir rocks. As it heats up, the polymer begins to expand to many times its original size, blocking pore throats and diverting water behind it (Pritchett et al, 2003; Frampton et al., 2004; Morgan 2007; Yanez et al., 2007; Garmeh et al., 2011). A pH sensitive polymer microgel uses the change in $\mathrm{pH}$ as an activation trigger. With increases in $\mathrm{pH}$, the gel begins to adsorb water, swelling up to 1000 times its initial volume (Al-Anazi et al., 2002; Huh et al., 2005; Benson et al., 2007). The primary differences between all of the current commercially preformed gels are the particle sizes, swelling ratios, and swelling times.

The millimeter-size particles of PPGs make them not only more distinguishable but also more reliable than other types of preformed gels for plugging large channeled features (Imqam et al., 2014). The success of gel treatments depends heavily on the gel's ability to reduce conductivity of these large channel features. Thus, understanding both the mechanism and the factors affecting the gel's ability to resist water flow through these channels are the main keys to achieving a successful conformance control treatment.

Much research has been conducted to study the rheology and factors affecting gel resistance to water flow. Grattoni et al. (2001) conducted a series of experimental work to link polymer gel properties (such as gel strength and polymer concentrations) to flow behavior. They found that permeability was a function of both water flow rate and polymer 
concentration. Yang et al. (2002) developed a mathematical model for the flow of water through channels impregnated with a polymer gel. Their results indicated that gels' intrinsic properties (e.g., gel reference permeability and elasticity index) controlled water flow behavior.

Previous experiments conducted by Zhang and Bai (2011) showed that millimeter-size particles formed a permeable gel pack in opening fractures rather than create full blocking. This paper will addresses the effect of brine concentration, particle size, and load pressure on the permeability of the PPG pack inside large channeled features. In addition, it will evaluate the ability of PPGs to reduce channel conductivity when the gel is subjected to the load pressure.

\section{Gel Pack Descriptions}

Previous fracture transparent model (Fig. 1) indicates that the PPG propagated like a piston along the fracture, and gravity did not change the shape of the front of the PPG if the particle size was larger than or close to the fracture width. The fracture transparent model was constructed of two acrylic plates with a rubber O-ring between them. Bolts and nuts were used to fix the two plates and control the fracture width. On one side of the plate, a hole functioned as an inlet for the injection of the brine and PPG; on the other side, another hole provided an outlet to discharge the brine and PPG. The model was transparent so that the movement of the PPG and brine would be clearly visible. In the case of the large channeling features, such as conduits, wormholes, and caves, understanding the gel pack permeability mechanism and determining which factors have a significant effect on the strength of the gel pack permeability is also needed to have a better PPG treatment design through these large feature systems. This paper describes factors that affect the gel pack permeability inside large channels and evaluates the gel pack compressibility in the presence of load pressure. The load pressure in this study refers to the pressure developed by a piston movement to compress the gel particles inside a transparent channel model.

\subsection{Gel pack permeability}

The PPG pack permeability was determined by measuring the differential pressures and flow rates while injecting brine through the gel pack-filled channel tube. The gel pack permeability was fitted according to the power law as follows:

$$
K_{P P G}=k_{o} v^{n}
$$

where $K_{P P G}$ is the preformed particle gel pack permeability, $k_{o}$ is the intrinsic permeability, $v$ is the superficial velocity, and $n$ is the gel elasticity index.

The permeability is a function of the flow velocity, following a nonlinear relationship. The link between velocity-dependent permeability and gel rheology has been proven experimentally, where increased brine injection flow rates enlarge the flow pathways within the PPG by elastic deformation. Power law behavior is usually observed when non-Newtonian fluid flows through a rigid porous medium. However, the brine used in this study is a Newtonian fluid, so the power law model can only 
be applied to the elastic properties of the PPG.

The intrinsic permeability and elasticity index are functions of fluid and gel properties. If $n$ equals zero, the permeability would not be velocity dependent; this could be the case if the PPG acted like a rigid porous medium. The deformability/elasticity of the PPG increases when $n$ is greater than 0 .

\subsection{Gel pack compressibility}

Gel pack compressibility is defined as the ability of gel particles to move closer to each other when the load pressure is applied against them. PPGs swollen in different brine concentrations were used to measure compressibility. The gel pack compressibility was measured by pouring gel particles inside the transparent model. The initial volume of gel inside the model was measured before applying the load pressure. A piston was then used to compress the gel by imposing different load pressures on the gel particles. For every load pressure that was tested, the gel continued to compress until no further water loss was produced from the gel as effluent. The change in volume and the pressure drop across the gel were both measured. This procedure was repeated for every brine concentration. In addition, the gel pack compressibility $\left(C_{p p g}\right)$ was calculated for every load pressure based on the following equation:

$$
\operatorname{Cppg}=\frac{-1}{V o} * \frac{\Delta V}{\Delta P_{g}}
$$

where Cppg is the PPG pack compressibility ( $\left.\mathrm{Psi}^{-1}\right), V_{o}$ is the initial PPG volume before compression $\left(\mathrm{cm}^{3}\right), \Delta V$ is the change in PPG volume after compression $\left(\mathrm{cm}^{3}\right)$, and $\Delta P_{g}$ is the change in pressure across the gel (psi).

\section{Experiment}

\subsection{Materials}

3.1.1. Preformed particle gel (PPG). A super absorbent polymer (SAP) was used as the preformed particle gel for this study. The particle was synthesized by a free radical process using acrylamide, acrylic acid, and N, N'-methylenebisacrylamide. Most PPGs reach full swelling in half an hour, but a field operation usually take a few hour to a few months, so we used fully swelling particles in our experiments.

The primary characteristics of the PPG used for the experiment are listed in Table 1.

Various sizes of PPG were selected for experiments: 18-20, 20-30, 50-60, and 80-100 mesh. Table 2 illustrates the PPG size distribution before and after being swollen in $1 \% \mathrm{NaCl}$ solution.

3.1.2. Brine Concentrations. Sodium chloride $(\mathrm{NaCl})$ with three concentrations $(0.05,1$, and $10 \mathrm{wt} \%)$ was used to prepare 
the swollen gels. Fig. 2 depicts the PPG before and after being swollen in different brine concentrations. The brine concentration was carefully selected according to the gel strenght and swelling ratio where the gel prepared in the low salinity brine had less strength and more swelling ratio than the gel prepared in the high salinity brine. Table 3 illustrates the swelling ratio and gel strength measurements for different brine concentrations. Storage moduli $\left(\mathrm{G}^{\prime}\right)$ for the PPG prepared in different brine concentrations were measured at room temperature $\left(23^{\circ} \mathrm{C}\right)$ using a rheometer. The sensor used for measurements was PP335 TiPoLO2 016, with a gap of $0.2 \mathrm{~mm}$ between the sensor and the plate. G' were measured at a frequency of $1 \mathrm{~Hz}$ for each sample.

\subsection{Experimental setup}

An apparatus was built to evaluate the factors impacting the permeability of the gel pack, as presented in Fig. 3. The apparatus (simple channel) was built from an acrylic transparent tube and its square cross-section was $5.06 \mathrm{~cm}^{2}$ and $26.5 \mathrm{~cm}$ long. Different brine concentrations were injected into the PPG-filled transparent tube, using a syringe pump. Two caps with four stainless steel rods and nuts were used to hold the transparent tube channel. The core sample was fitted inside the tube with an O-ring to prevent any leakage of gel that might occur during brine injection. A piston made from an acrylic rod was located at the top of the tube to compress the gel inside the channel tube. A hole inside the piston was made to permit brine to be injected through the gel after it was compressed. Two pressure gauges were connected, one at the inlet and the other at the bottom of the gel, to measure the differential pressure across the PPG.

\subsection{Experimental procedure}

A consolidated sandstone core was fitted at the bottom of the channel tube model to prevent gel movement from reaching the outlet. Swollen PPG was then placed inside the transparent tube model. Six different injection brine flow rates $(0.1,0.2,0.3,0.4,0.5$, and $0.6 \mathrm{ml} / \mathrm{min})$ were used for each experiment to measure the PPG pack permeability.

A piston was then fitted inside the channel, and the gel was compressed at eight different load pressures: 75, 125, 150, 175, 200, 225, 250, and 275 psi. At each load pressure, the same injection flow rates were used to measure the gel pack permeability. The pressure drop across the PPG, the change in the length of the gel, and the fluid produced at the outlet were all recorded at the ambient temperature. In addition, to study the effect of load pressure on gel strength measurements, a sample of gel was taken before and after the gel was compressed.

\section{Results and Analysis}

\section{1. $P P G$ pack permeability measurements}

4.1.1. Brine concentration effect

Stabilized pressures for each concentration of brine were obtained at the different injection flow rates (Fig 4). The results showed that the stabilized pressure of the PPG rose as the flow rate increased. This increase, however, was significant only at a low flow rate $(0.1$ to $0.3 \mathrm{ml} / \mathrm{min})$. For example, in the case of no piston effect, the stabilized pressure for the gel 
swollen in $10 \%$ brine started to increase from 1 psi to $2.8 \mathrm{psi}$ at low flow rates $(0.1$ to $0.3 \mathrm{ml} / \mathrm{min})$. At high flow rates $(0.4$ to $0.6 \mathrm{ml} / \mathrm{min}$ ), the pressure slightly increased from 3.5 to 4.1 psi. Additionally, Fig. 4 provides a gel stabilized pressure comparison between the brine concentrations of $0.05 \% \mathrm{NaCl}$ and $10 \% \mathrm{NaCl}$ before and after the load pressure was introduced. The results showed that the pressure measurement at $0.05 \%$ did not increase significantly after the gel was compressed to $275 \mathrm{psi}$ as compared to the results for the $10 \%$ solution. The pressure measurement increased almost 1 psi for the former and almost 13 psi for the latter. This behavior revealed that the permeability of a strong gel (swollen in a high brine concentrations) decreased more rapidly than that of a weak gel (swollen in a low brine concentrations) if high pressure was applied. All the measurements of gel particle compression were performed until 275 psi because it was observed that the gel pack permeability became almost at higher pressure. The results suggest that strong gel applications in an oil field will be more effective than weak gels at controlling water production.

The PPG pack permeability calculated for the different brine concentrations was determined according to the power law equation and plotted as shown in Fig. 5. At the initial load pressure, gel swollen in $10 \% \mathrm{NaCl}$ started with a higher gel pack permeability than did gels swollen in either $0.05 \% \mathrm{NaCl}$ or $1 \% \mathrm{NaCl}$. The gel pack permeability with a $10 \%$ brine concentration started at $103 \mathrm{md}$ before the gel was compressed. The gel compressed gradually when the load pressure was applied. The gel pack permeability began to decrease continuously until $200 \mathrm{psi}$, it fluctuated between 5 and $7 \mathrm{md}$. The gel pack permeability with a $0.05 \% \mathrm{NaCl}$ brine began at $20 \mathrm{md}$ before the load pressure was applied. It started decreasing after the load pressure was applied. When the load pressure reached $175 \mathrm{psi}$, the gel pack permeability had a different trend. It started to form channels inside the gel, and the permeability increased to $11.8 \mathrm{md}$. When the pressure was released, the gel network reformed and the gel pack permeability continued to decrease after the gel compressed to $200 \mathrm{psi}$.

Fig. 5 indicates also that the strong gel had a higher gel pack permeability than did a weak gel before the load pressure was introduced. At a high load pressure, however, the gel pack permeability exhibited a different trend. The decrease in the PPG pack permeability with a high gel strength was significantly less than that of the PPG pack permeability with a low gel strength.

Tables 4, 5, and 6 summarize both the permeability and elasticity measurements for the different brine concentrations as determined by using the power law equation. The elasticity index for the PPG varied between 0.7 and 0.9 for weak gels, while for strong gels, it varied between 0.3 and 0.8 .

\subsubsection{Preformed particle gel size effect}

Various particle sizes were used to investigate how the PPG size affects the permeability measurements. Particles of all experimental sizes were swollen in the same brine concentrations $(1 \% \mathrm{NaCl})$. Fig. 6 reveals that the PPG pack permeability was affected by particle size. Large particle sizes had a lower gel pack permeability than did smaller particle sizes across all 
of the load pressure ranges. The gel pack permeability with a particle size of 20-30 mesh was 27 md before adding the load pressure. The gel pack permeability then started to decrease gradually after the load pressure was introduced. The permeability decreased to almost $8 \mathrm{md}$ at $200 \mathrm{psi}$. Gel with a particle size of 80-100 mesh had a gel pack permeability of 33 md before applying the load pressure. Permeability then decreased to almost 20 md at 200s psi. In addition, the results showed that the PPG pack permeability before applying the load pressure was much larger than the PPG pack permeability after applying the load pressure. The PPG pack permeability decreased significantly when the load pressure was first applied. The permeability then became almost constant because the gel particles were compressed substantially, forcing them closer to one another during the earlier stages of the applied load pressure and less during the later stages. Similarly, this new finding indicated that the PPG pack permeability would have lower permeability at reservoir pressure conditions than it would at surface conditions. It also suggested that using smaller particles in the conformance control treatment would not result in a better gel resistance to water flow inside the high permeability channels.

\subsection{Effect of brine concentration and particle size on gel pack permeability reduction}

This section presents a comparison between the gel pack permeability determined before and after load pressure for both effects of brine concentration and particle size. The results obtained from this comparison are important to quantifying the change in the gel permeability and the rheology that occurred during the PPG compression.

\subsubsection{Reduction of PPG pack permeability for various brine concentrations}

The effect of brine concentration on the PPG pack permeability can be expressed using the Permeability Gel Reduction (KGR) factor. It can be defined as the ratio between the PPG pack permeability measured after using the load pressure (KGA) and the PPG pack permeability measured before the load pressure (KGB). This concept, which is expressed in a percentage, is used to determine how much the PPG permeability can be decreased.

Table 7 illustrates the permeability results obtained for 30-mesh size PPG swollen in three different brine concentrations. The results indicated that the KGB increased as the brine concentration increased. When the load pressure was applied, however, the KGA decreased as the brine concentration increased. Consequently, the PPG permeability reduction (KGR \%) rose as the gel strength increased. The KGR for a gel swollen in $0.05 \% \mathrm{NaCl}$ was $54.05 \%$; the KGR for a gel swollen in $10 \%$ $\mathrm{NaCl}$ was $94.73 \%$. These results suggested that the plugging efficiency can be improved if a strong gel is selected for the conformance control treatment.

\subsubsection{Reduction of the PPG pack permeability for various particle sizes}

Table 8 displays the effect of different particle sizes on the PPG pack permeability reduction. Particles of various sizes were swollen in the same brine concentration $(1 \% \mathrm{NaCl})$. The findings show that the PPG pack permeability before and after applying the load pressure was greater for smaller particle sizes than for larger particle sizes. The PPG permeability reduction 
(KGR \%) did not significantly change for the experimental particle sizes. Compared with the effect of brine concentration, particle size had less effect on the KGR.

\subsubsection{PPG strength}

A rheometer was used to measure the strength of the gel swollen in $0.05,1$, or $10 \% \mathrm{NaCl}$. Fig. 7 presents the PPG strength measurements before and after the load pressure was applied. G`A and $\mathrm{G}^{`} \mathrm{~B}$ are gel strengths measured before and after the load pressure was introduced, respectively. The results suggested that the gel strength increased as the brine concentration and load pressure increased. Analogously, this result revealed that the gel strength would increase when gel is injected into the target formation under reservoir pressure conditions.

\subsection{PPG compressibility measurement}

The results obtained from our experiments demonstrated that the PPG can be compressed at various values based on both different brine concentrations and load pressures. Gel compressibility was obtained and plotted in Fig. 8 for the different brine concentrations. The PPG for all brine concentrations had a large compressibility value at the beginning of the introduced load pressure. For instance, the PPG swollen in $10 \% \mathrm{NaCl}$ had a compressibility of $0.0037 \mathrm{psi}^{-1}$ at 75 psi and then decreased gradually to $0.00172 \mathrm{psi}^{-1}$ at $275 \mathrm{psi}$. The findings obtained from the compressibility measurements are consistent with data obtained from the PPG pack permeability measurements. At the initial load pressure of 75 psi, the gel compressibility of the solution with $10 \% \mathrm{NaCl}$ was $0.0037 \mathrm{psi}^{-1}$, while the gel compressibility of the $1 \%$ brine concentration at $75 \mathrm{psi}$ load pressure was only $0.000527 \mathrm{psi}^{-1}$. The compressibility for both brine concentrations $1 \% \mathrm{NaCl}$ and $10 \% \mathrm{NaCl}$ is fairly fitted by Eq. 3 and Eq. 4, respectively, as follows:

$$
\begin{aligned}
& C_{p p g}=0.0091 P^{-0.614} \\
& C_{p p g}=0.0437 P^{-0.573}
\end{aligned}
$$

Additionally, the results in Fig. 8 indicated that the compressibility for a PPG swollen in $0.05 \% \mathrm{NaCl}$ decreased gradually and then suddenly increased at $175 \mathrm{psi}$. This increase most likely occurred due to the channel created during the PPG permeability measurement process. Data also suggested that PPGs swollen in high brine concentrations are more compressible than PPGs swollen in low brine concentrations. The average PPG compressibility obtained for all brine concentrations ranged between $0.0003 \mathrm{psi}^{-1}$ and $0.003 \mathrm{psi}^{-1}$. Table 9 shows the procedure for finding the compressibility in relation to the load pressure.

\section{Discussion}

\subsection{PPG pack permeability is velocity dependent}

The PPG pack permeability was obtained for water flow through the gel-filled channel tube. The Darcy law for flow through porous media (Eq. 5) was used to measure the PPG pack permeability: 


$$
v=\frac{\mathrm{Q}}{\mathrm{A}}=\frac{-K \Delta P}{\mu \mathrm{L}}
$$

where $Q\left(\mathrm{~cm}^{3} / \mathrm{s}\right)$ is the flow rate, $A\left(\mathrm{~cm}^{2}\right)$ is the cross-sectional area, $\Delta_{P}(\mathrm{~atm})$ is the pressure drop over the length $L(\mathrm{~cm})$ of the gel, $\mu(\mathrm{cp})$ is the fluid viscosity, and $K(\mathrm{md})$ is the permeability.

Because the gel is composed of shear-thinning or pseudoplastic materials, we observed that the PPG pack permeability measurements for the different brine concentrations and particle sizes were not constant. Instead, the measurements revealed that the PPG was velocity dependent, following a nonlinear relationship. Additionally, the PPG permeability was dependent not only on the velocity of the brine injected but also on the elasticity index of the gels. Therefore, all results for the PPG permeability were fitted according to the power law model. We also observed that increases in the injection flow rate caused a rise in the gel pack permeability and also deformed the gel in a manner that was proportional to the applied pressure.

\subsection{Preformed particle gel deformations}

The change in both the PPG pack permeability and rheological properties caused by gel deformation during brine flow can be addressed as follows:

5.2.1. PPG strength: Results obtained from the rheometer (Fig. 7) show that the gel rheology changed after the load pressure was introduced. This feature is an advantage for the PPG because the gel became stronger than it was at surface conditions. Thus, a better water flow control can be achieved in large channeled reservoirs. Gel strengths measured after the load pressures were correlated with the PPG pack permeability are shown in Fig. 9. The power law model equation for the gel pack permeability was obtained as a function of gel strength.

5.2.2. PPG compressibility: The PPG compressibility plays a crucial role in controlling water production. If the gel can be compressed using a high pressure, the plugging efficiency of the gel will be increased. This happens because the gel particles can move closer to each other and minimize the possibility that there is any open pore size during water flow. Consequently, water will be trapped behind the gel and cannot move further.

The results demonstrate that the PPGs can be compressed at different values based on the gel strength difference. This is the first study to report this feature of the PPG, and more research is needed to compare the traditional gel compressibility with the PPG.

5.2.3. $P P G$ elasticity: The elasticity index for the PPG at different gel strengths was measured after applying the load pressure (Table 10). These findings reveal that the gel storage model $\left(\mathrm{G}^{\prime}\right)$ increased as the elasticity index decreased. The 
306

blocking efficiency of the PPG was significantly affected by the gel strength. Gels with high storage moduli would be preferable for conformance control field applications.

\section{Conclusions}

During these investigations of factors affecting the gel pack permeability formed inside large channeled features, we observed these conclusions:

- A PPG partially blocks the large channel rather than fully blocking it. The PPG will do so because the gel can formed channels for water to pass through. Therefore, we strongly recommend that operators in the field consider the effect of both particle size and brine concentration when designing PPGs for water production control purposes.

- Gel-plugging efficiency is affected by particle size selection. Our results indicated that gel resistance to water flow improved when larger particles were selected.

- Brine concentration had a significant effect on the PPG resistance to water flow. We observed that strong gels had a lower permeability than did weak gels. Therefore, a strong PPG would be the right choice for more effectively plugging an undesired zone than a weak gel.

- Brine concentration had a more pronounced effect on the PPG pack permeability than did gel particle size.

- The gel pack permeability decreased significantly at the beginning of the compression process. Then, after the gel became slightly rigid because of the load pressure effect, the compressibility reduction became less obvious. The PPG was compressible between $0.0003 \mathrm{psi}^{-1}$ and $0.003 \mathrm{psi}^{-1}$. This compressibility varied according to both brine concentration and particle size.

- The PPG strength increased as both the brine concentration and the load pressure increased. A weak gel creates internal channels more easily than a strong gel when the PPG is subjected to continuous load pressure.

- Gel pack permeability is lower at reservoir conditions compared to the gel pack permeability at surface conditions. The gel pack permeability measurements registered a few hundred millidarcies before the load pressure was applied; the gel permeability decreased to less than $10 \mathrm{md}$ after the load pressure was introduced.

\section{Acknowledgements}

The authors would like to express their grateful acknowledge for Research Partnership to Secure Energy for America (RPSEA) and the US Department of Energy for their financial support of this project. The authors also would like to express their appreciation to the High Ministry of Education in Libya for its support. 


\section{References}

Al-Anazi, H.A. and Sharma, M.M. 2002. Use of pH Sensitive Polymer for Conformance Control. Paper SPE 73782 presented at the International Symposium and Exhibition on Formation Damage Control, Lafayette, Louisiana, USA, 20-21 February.doi: $10.2118 / 73782 \mathrm{M}$

Bai, B., Li, L., Liu, Y., Liu, H., Wang, Z., and You, C. 2007a. Preformed particle gel for Conformance Control: Factors Affecting its Properties and Applications. SPE Res Eval \& Eng 10 (4): 415-421. SPE-89389-PA. Doi: 10.2118/89389-PA.

Bai, B., Liu, Y., Coste, J.-P., and Li, L. 2007b. Preformed particle gel for Conformance Control: Transport Mechanism through Porous Media. SPE Res Eval \& Eng 10 (2): 176-184. SPE-89468-PA. Doi: 10.2118/89468-PA.

Benson I., Nghiem L.X., Bryant S.L., Sharma M.M. and Huh C.2007. Development and Use of a Simulation Model for Mobility/Conformance Control Using a pH-Sensitive Polymer. Paper SPE 109665 presented at SPE Annual Technical Conference and Exhibition, California, 11-14 November .doi: 10.2118/109665-MS.

Chauveteau, G., Tabary, R., Renard, M., and Omari, A. 1999. Controlling In-Situ Gelation of Polyacrylamides by Zirconium for Water Shutoff. Paper SPE 50752 presented at the SPE International Symposium on Oilfield Chemistry, Houston, 16-19 February. Doi: 10.2118/50752-MS.

Chauveteau, G., Omari, A., Tabary, R., Renard, M., Veerapen, J., and Rose, J. 2001. New Size-Controlled Microgels for Oil Production. Paper SPE 64988 presented at the SPE International Symposium on Oilfield Chemistry, Houston, 13-16 February. Doi: $10.2118 / 64988-\mathrm{MS}$.

Chauveteau, G., Tabary, R., le Bon, C., Renard, M., Feng, Y., and Omari, A. 2003. In-Depth Permeability Control by Adsorption of Soft Size-Controlled Microgels. Paper SPE 82228 presented at SPE Euro-pean Formation Damage Conference, The Hague, 13-14 May. Doi: 10.2118/82228-MS.

Coste, J.-P., Liu, Y., Bai, B., Li, Y., Shen, P., Wang, Z., and Zhu, G. 2000. In-Depth FLuid Diversion by Pre-Gelled Particles. Laboratory Study and Pilot Testing. Paper SPE 59362 presented at the SPE/DOE Improved Oil Recovery Symposium, Tulsa, 3-5 April. Doi: 10.2118/59362-MS.

Frampton, H., Morgan, J.C., Cheung, S.K., Munson, L., Chang, K.T., and Williams, D. 2004. Development of a Novel Water flood Conformance Control System. Paper SPE 89391 presented at the SPE/DOE Symposium on Improved Oil Recovery, Tulsa, 17-21 April. Doi: 10.2118/89391-MS.

Garmeh R., Izadi M., Salehi M., Romero J.L., Thomas C.P. and Manrique E.J.2011 .Thermally Active Polymer to Improve Sweep Efficiency of Water Floods: Simulation and Pilot Design Approaches. Paper SPE 144234 presented at Enhanced Oil Recovery Conference, Kuala Lumpur, 19-21 July. Doi: 10.2118/144234-MS

Grattoni, C.A., Al-Sharji, H.H., Yang, C., Muggeridge, A.H., and Zimmerman, R.W. 2001. Rheology and Permeability of Crosslinked Polyacrylamide Gel. Journal of Colloid and Interface Science 240: 601-607.doi:10.1006/jcis.2001.7633.

Huh, C., Choi, S.K., and Sharma, M.M. 2005. A Rheological Model for pH-Sensitive Ionic Polymer Solutions for Optimal MobilityControl Applications. Paper SPE 96914 presented at the SPE Annual Technical Conference and Exhibition, Dallas, 9-12 October. Doi: 10.2118/96914-MS.

Imqam, A., Bai, B., Al-Ramadan, M., et al. 2014. Preformed particle gel Extrusion through Open Conduits during Conformance Control

Treatments. Paper SPE 169107 presented at the SPE Improved Oil Recovery Symposium, Tulsa, Oklahoma, 12-16 April.

Morgan N.: "Pop Goes the Polymer", BP Frontiers (December 2007), pp. 6-9.

Pritchett, J., Frampton, H., Brinkman, J., Cheung, S, Morgan, J., Chang, K.T., Williams, D., and Goodgame, J. 2003. Field Application of a New In-Depth Water flood Conformance Improvement Tool. Paper SPE 84897 presented at the SPE International Improved Oil Recovery Conference in Asia Pacific, Kuala Lumpur, 20-21 October. Doi: 10.2118/84897-MS.

Rousseau, D., Chauveteau, G., Renard, M., Tabary, R., Zaitoun, A., Mallo, P., Braun, O., and Omari, A. 2005. Rheology and Transport in Porous Media of New Water Shutoff/Conformance Control Microgels. Paper SPE 93254 presented at the SPE International Symposium on Oilfield Chemistry, Houston, 2-4 February. Doi: 10.2118/93254-MS.

Yanez P.A.P., Mustoni J.L., Relling M.F., Chang K.T., Hopkinson P. and Frampton H.2007. New Attempt in Improving Sweep Efficiency at the Mature Koluel Kaike and Piedra Clavada Water flooding Projects of the S. Jorge Basin in Argentina. Paper SPE 107923 presented at Latin American and Caribbean Petroleum Engineering Conference, Buenos Aires, 15-18 April .doi: 10.2118/107923-MS

Yang, C., Grattoni, C.A., Muggeridge, A.H., and Zimmerman, R.W. 2002 .Flow of water through channels Filled with Deformable Polymer Gels.Journal of Colloid and Interface Science 250: 466-470.doi:10.1006/jcis.2002.8325.

Zaitoun, A., Tabary, R., Rousseau, D., Pichery, T., Nouyoux, S., Mallo, P., and Braun, O. 2007. Using Microgels to Shut Off Water in a Gas Storage Well. Paper SPE 106042 presented at the SPE International Symposium on Oilfield Chemistry, Houston, 28 February2 March. Doi: 10.2118/106042-MS.

Zhang, H., and Bai, B. 2011 Preformed particle gel Transport through Open Fracture and its Effect on Water Flow. SPE Journal 16(2): 388-400. SPE-129908-PA. DOI: 10.2118/129908-PA 
Table 1. Typical characteristics of PPG

\begin{tabular}{cc}
\hline Properties & Value \\
\hline Absorption of Deionized Water $(\mathrm{g} / \mathrm{g})$ & $>200$ \\
Apparent Bulk Density $(\mathrm{g} / \mathrm{l})$ & 540 \\
Moisture Content $(\%)$ & 5 \\
$\mathrm{pH}$ Value & $5.5-6.0(+/-0.5 ; 1 \%$ gel in $0.9 \% \mathrm{NaCl})$ \\
\hline
\end{tabular}

Table 2. PPG size before and after being swollen in $1 \% \mathrm{NaCl}$

\begin{tabular}{|c|c|c|c|}
\hline \multicolumn{4}{|c|}{ TABLE-2 PPG SIZE BEFORE AND AFTER BEING SWOLLEN IN $1 \% \mathrm{NaCl}$} \\
\hline$\underline{\text { No }}$ & $\underline{P P G \text { (mesh size) }}$ & PPG size before being swollen, $\mu \mathrm{m}$ & PPG size after being swollen, $\mathrm{mm}$ \\
\hline 1 & $18-20$ & 850 & 42.5 \\
\hline 2 & $20-30$ & 600 & 30 \\
\hline 3 & $50-60$ & 250 & 12.5 \\
\hline 4 & $80-100$ & 150 & 7.5 \\
\hline
\end{tabular}

Table 3. PPG swelling ratio and strength measurements

\begin{tabular}{|c|c|c|c|c|}
\hline \multicolumn{5}{|c|}{ TABLE-3 SWELLING AND GEL STRENGTH MEASUREMENTS OF 30-MESH PPG } \\
\hline No & Brine concentration, $\% \mathrm{NaCl}$ & PPG concentration, wt \% & Swelling ratio & Gel strength, pa \\
\hline 1 & 0.05 & 0.60 & 165 & 515 \\
\hline 2 & 1 & 2.0 & 50 & 870 \\
\hline 3 & 10 & 4.0 & 25 & 1300 \\
\hline
\end{tabular}

Table 4. PPG pack permeability measurements for $0.05 \% \mathrm{NaCl}$

\begin{tabular}{cccc}
\hline P (psi) & Intrinsic Permeability, ko (md) & Elasticity Index & $R^{2}$ \\
\hline No load & 19.987 & 0.8417 & 0.9916 \\
75 & 14.105 & 0.7792 & 0.991 \\
125 & 13.316 & 0.7555 & 0.9803 \\
150 & 11.196 & 0.9418 & 0.9986 \\
175 & 11.856 & 0.9661 & 0.9901 \\
200 & 14.594 & 0.7939 & 0.9159 \\
225 & 13.201 & 1.381 & 0.9693 \\
250 & 10.182 & 0.9003 & 0.9961 \\
275 & 9.1823 & 0.9444 & \\
\hline
\end{tabular}


Table 5. PPG pack permeability measurements for $1 \% \mathrm{NaCl}$

\begin{tabular}{cccc}
\hline P (psi) & Intrinsic Permeability, ko (md) & Elasticity Index & $R^{2}$ \\
\hline No load & 27.114 & 0.8399 & 0.992 \\
75 & 19.185 & 0.8464 & 0.9964 \\
125 & 15.035 & 0.7729 & 0.9956 \\
150 & 11.889 & 0.8575 & 0.9988 \\
175 & 10.345 & 0.8055 & 0.9937 \\
200 & 9.1845 & 0.8934 & 0.999 \\
225 & 8.2749 & 0.9505 & 0.9963 \\
250 & 7.4038 & 0.9349 & 0.997 \\
\hline
\end{tabular}

Table 6. PPG pack permeability measurements for $10 \% \mathrm{NaCl}$

\begin{tabular}{cccc}
\hline $\mathrm{P}(\mathrm{psi})$ & Intrinsic Permeability, ko $(\mathrm{md})$ & Elasticity Index & $\mathrm{R}^{2}$ \\
\hline No load & 103.53 & 0.311 & 0.9372 \\
75 & 74.323 & 0.1297 & 0.9699 \\
125 & 22.643 & 0.4809 & 0.9287 \\
150 & 12.809 & 0.6346 & 0.9743 \\
175 & 6.4912 & 0.5848 & 0.9308 \\
200 & 3.3611 & 0.8532 & 0.9963 \\
225 & 7.5038 & 0.7202 & 0.9833 \\
250 & 5.9863 & 0.6923 & 0.9659 \\
275 & 5.4555 & 0.7136 & 0.9606 \\
\hline
\end{tabular}


Table 7. Reduction of the PPG pack permeability after applying load pressure as a function of brine concentration

\begin{tabular}{ccccc}
\hline Particle Size (mesh) & Brine Concentration, \% NaCl & KGB & KGA@275psi & KGR (\%) \\
\hline 30 & 0.05 & 19.987 & 9.1823 & 54.05 \\
30 & 1 & 27.114 & 7.4382 & 72.56 \\
30 & 10 & 103.53 & 5.455 & 94.73 \\
\hline
\end{tabular}

Table 8. Reduction of PPG pack permeability after applying load pressure as a function of particle size

\begin{tabular}{ccccc}
\hline Brine Concentration \% NaCl & Particle Size (mesh) & KGB & KGA@275 psi & KGR \% \\
\hline 1 & $18-20$ & 22.201 & 6.167 & 72.2 \\
1 & $20-30$ & 27.114 & 7.4382 & 32.56 \\
1 & $50-60$ & 27.351 & 16.846 & 38.4 \\
1 & $80-100$ & 32.756 & 19.592 & 40.1 \\
\hline
\end{tabular}

Table 9. Compressibility of 30 -mesh size with $1 \% \mathrm{NaCl}$

\begin{tabular}{ccccccc}
\hline $\mathrm{P}(\mathrm{psi})$ & $\mathrm{L}$ & $\mathrm{Vo}$ & $\mathrm{V} 2$ & Delt V & Delt P & ${\text { Cppg }\left(\mathrm{Ps} \mathrm{i}^{-1}\right)}$ \\
\hline 75 & 22.5 & 118.5093 & 113.9513 & 4.55805 & 73 & 0.000527 \\
125 & 22.4 & 118.5093 & 113.4448 & 5.0645 & 123 & 0.000347 \\
150 & 22.3 & 118.5093 & 112.9384 & 5.57095 & 147 & 0.00032 \\
175 & 22.1 & 118.5093 & 111.9255 & 6.58385 & 173 & 0.000321 \\
200 & 21.9 & 118.5093 & 110.9126 & 7.59675 & 198 & 0.000324 \\
225 & 21.7 & 118.5093 & 109.8997 & 8.60965 & 223 & 0.000326 \\
250 & 21.6 & 118.5093 & 109.3932 & 9.1161 & 250 & 0.000308 \\
275 & 21.5 & 118.5093 & 108.8868 & 9.62255 & 273 & 0.000297 \\
\hline
\end{tabular}

Table 10. PPG permeability as a function of elasticity index and storage model

\begin{tabular}{cccc}
\hline Brine concentration \% NaCl & Effective Permeability & Elasticity Index & Storage Moduli G (Pa) \\
\hline 0.05 & 9.1823 & 0.944 & 650 \\
1 & 7.4382 & 0.919 & 920 \\
10 & 5.455 & 0.713 & 1360 \\
\hline
\end{tabular}




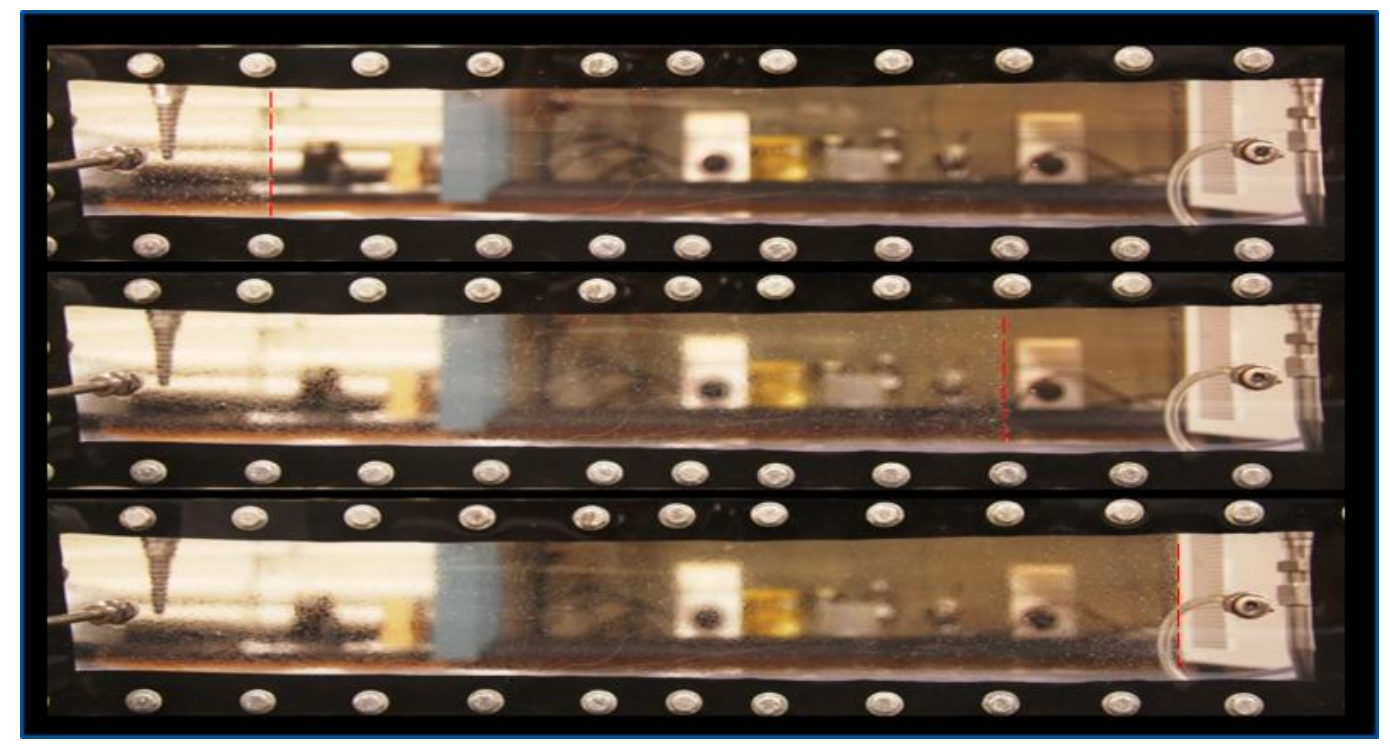

Fig. 1. PPG propagates like a piston (Zhang and Bai, 2011).
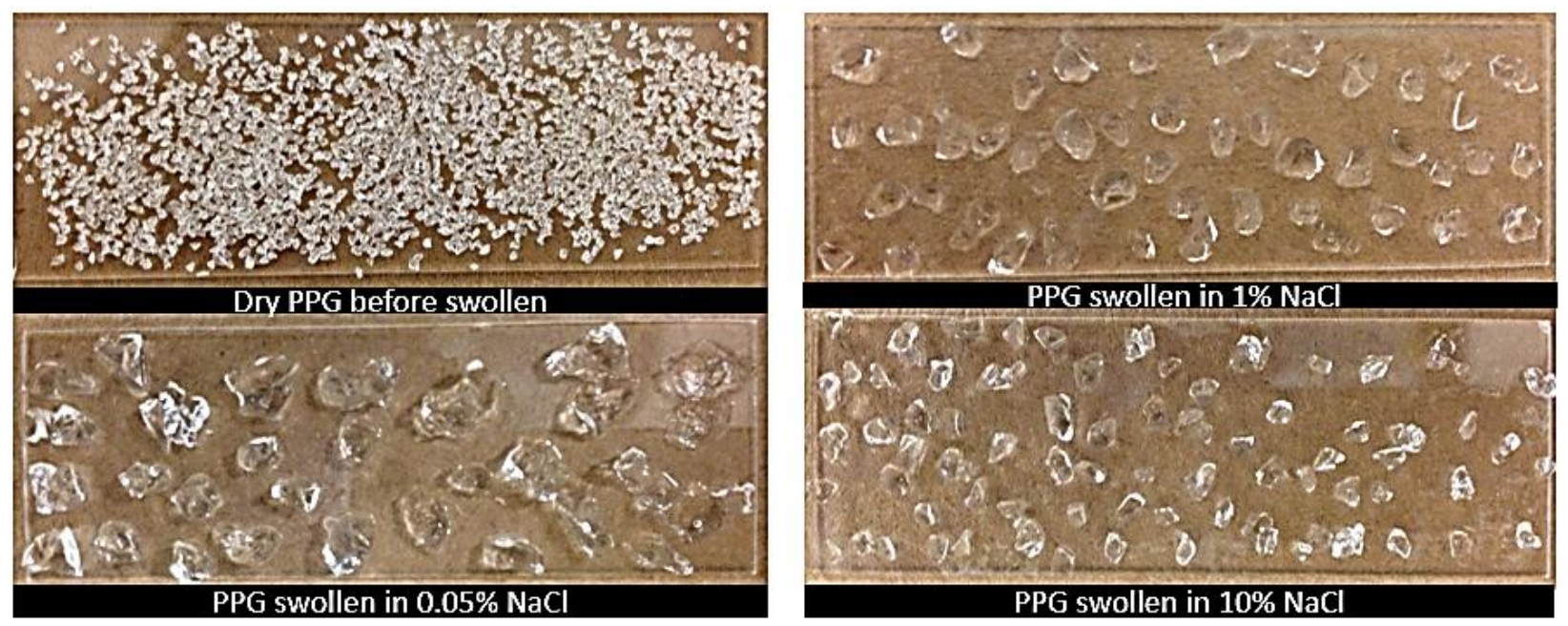

Fig. 2. PPG (30-mesh size) before and after being swollen in different brine concentrations. 


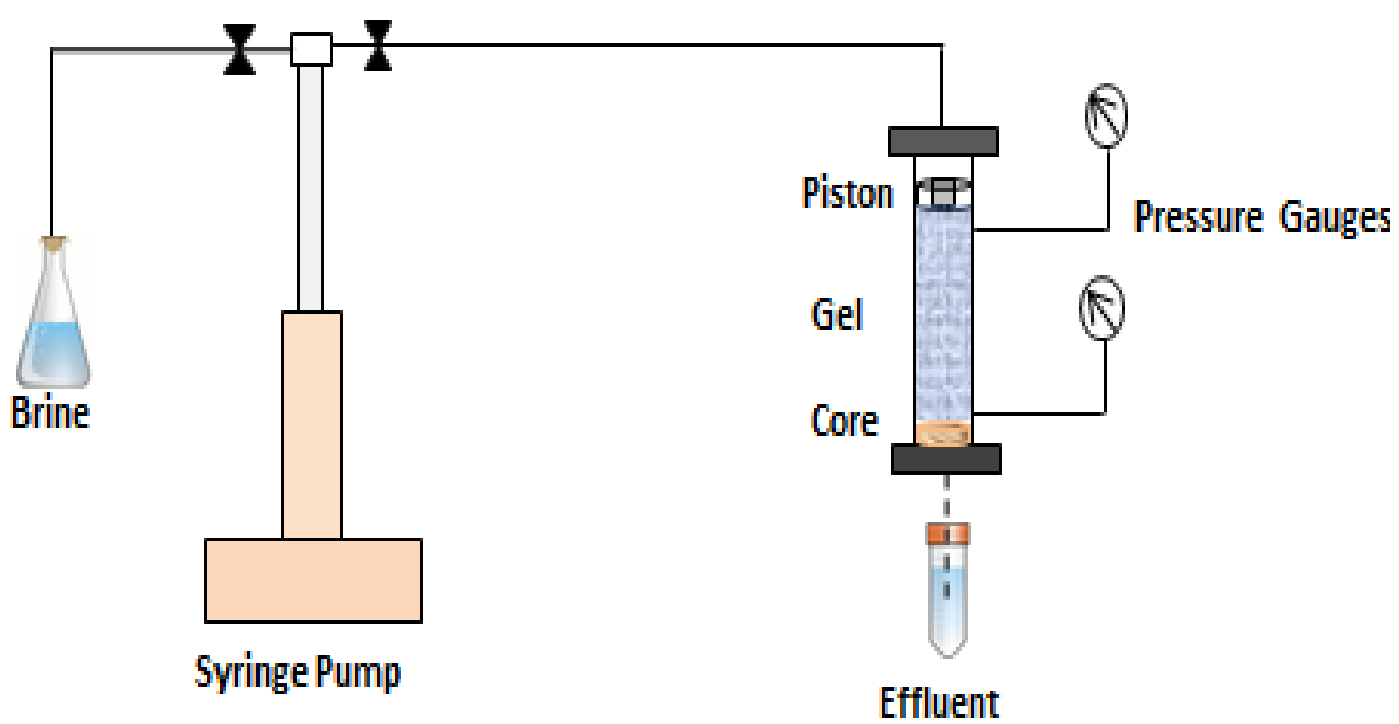

Fig. 3. PPG permeability measurement setup showing the effect of load pressure. 


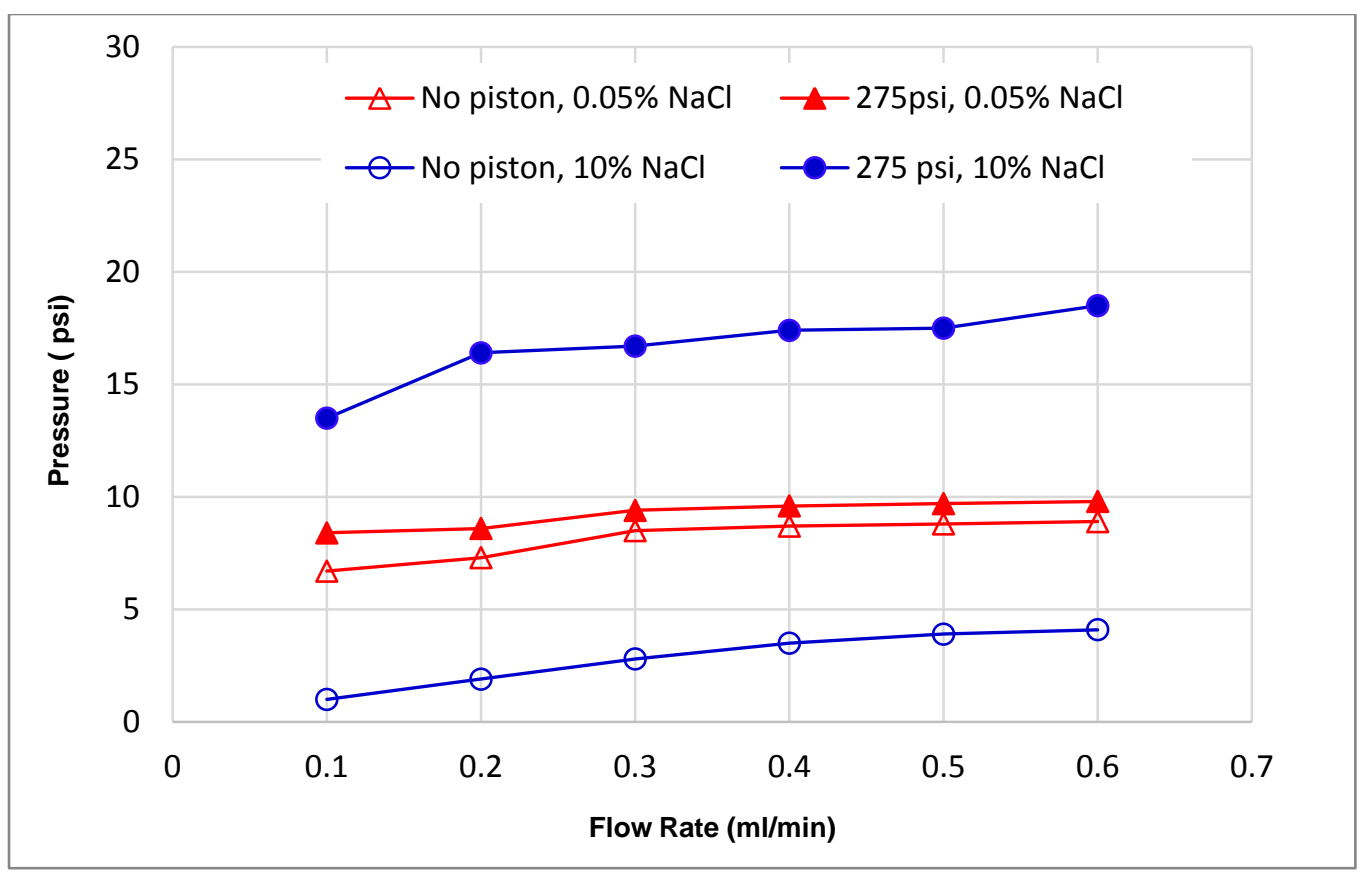

Fig. 4. Stabilized pressure for different brine concentrations before and after applying load pressure.

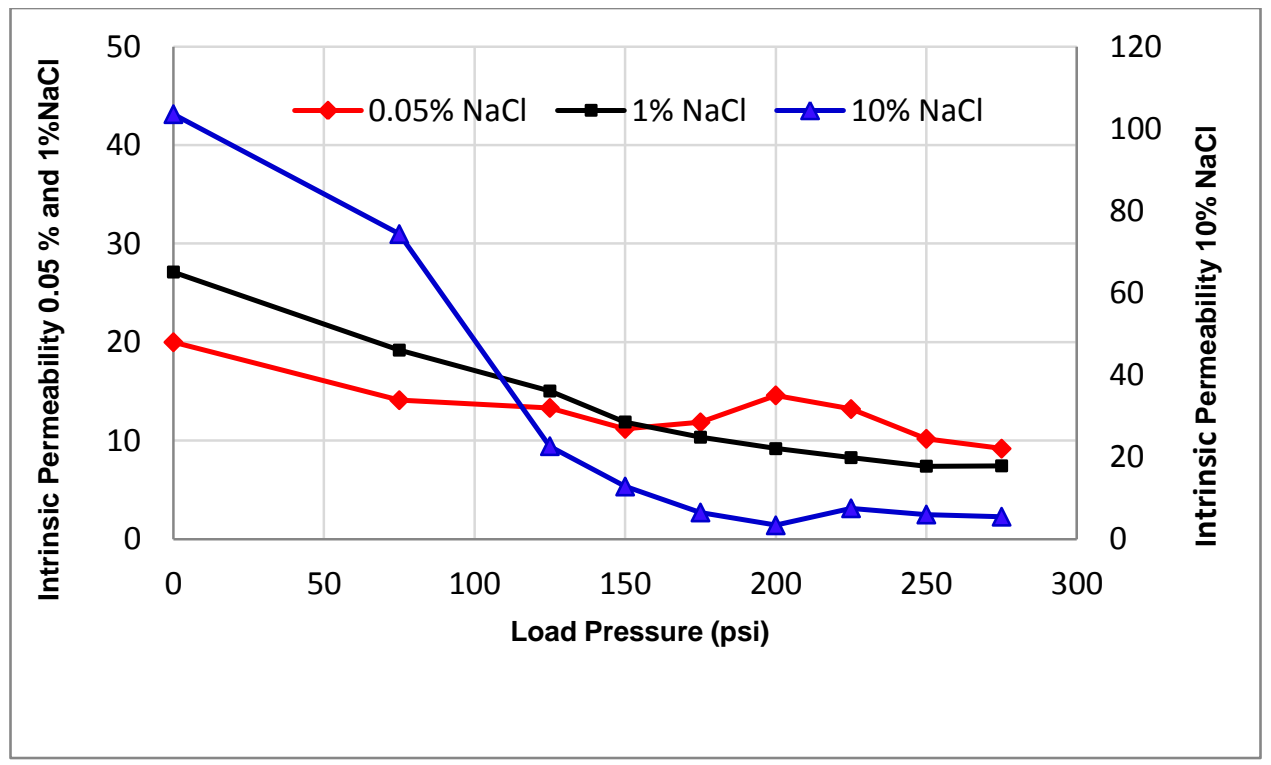

Fig. 5. Comparison between PPG pack permeabilities with different brine concentrations. 


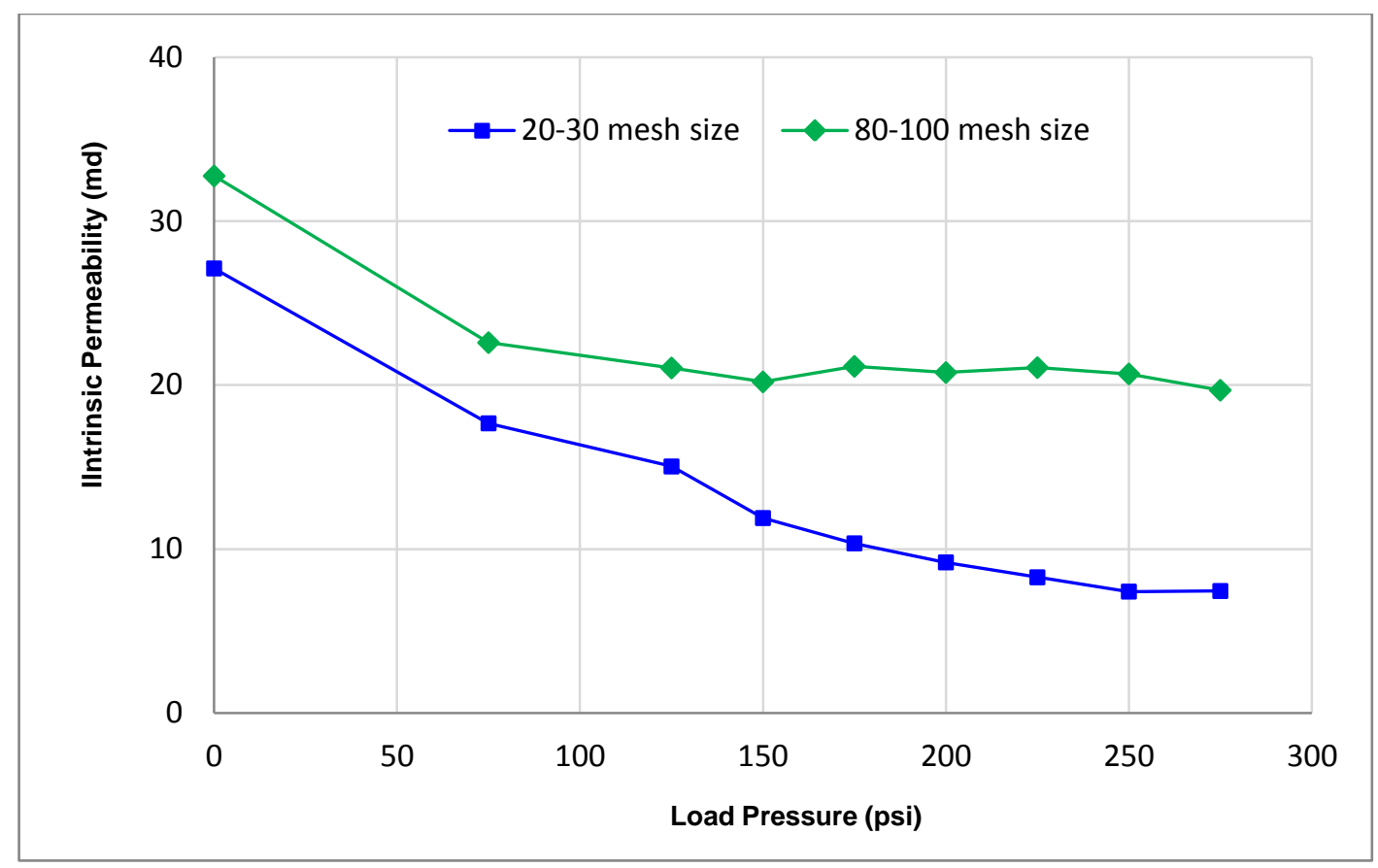

Fig. 6. Comparison between PPG pack permeabilities with different particle sizes.

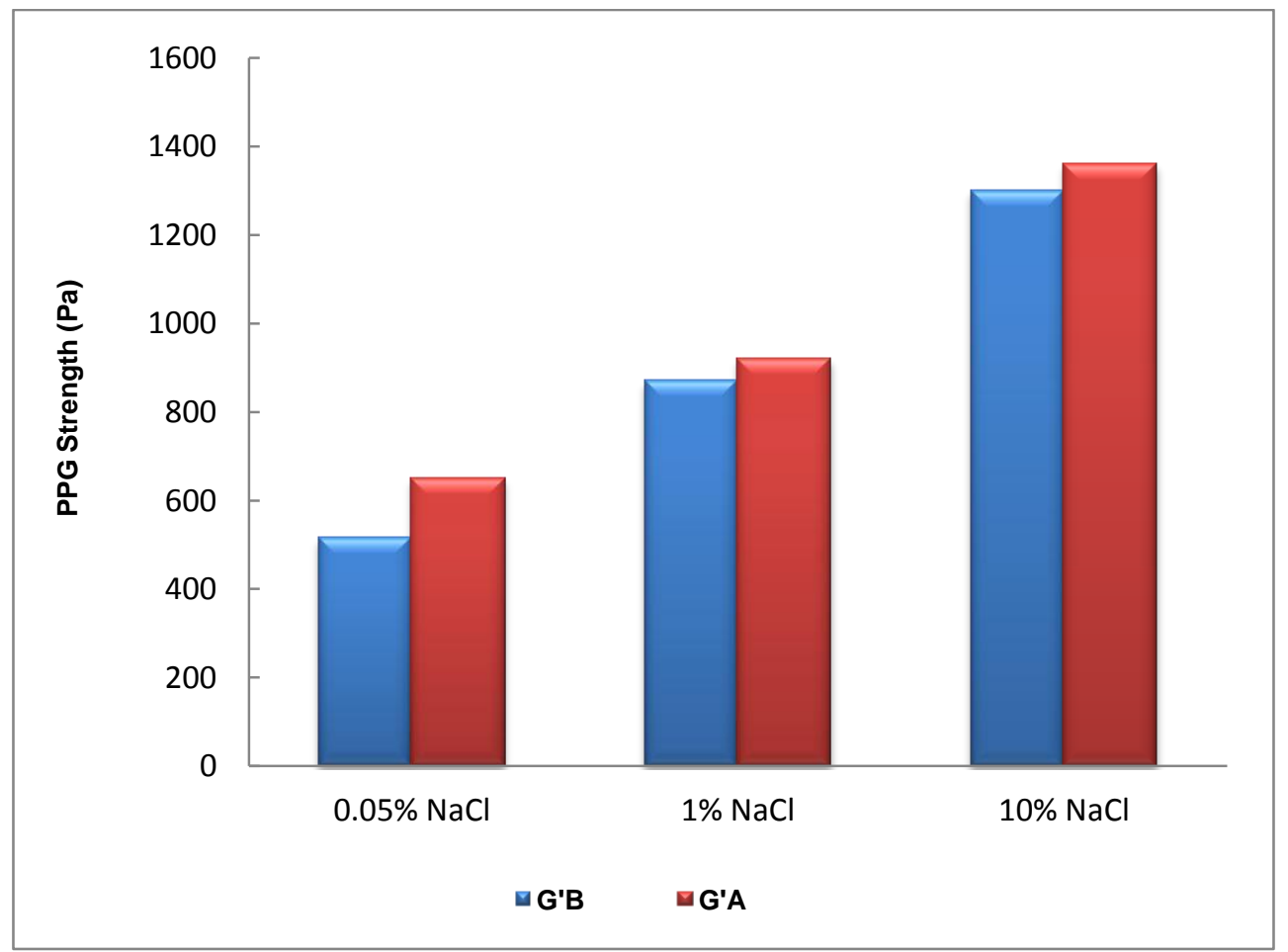

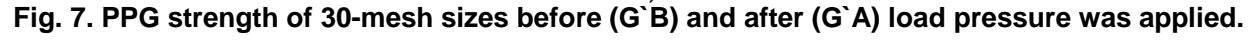




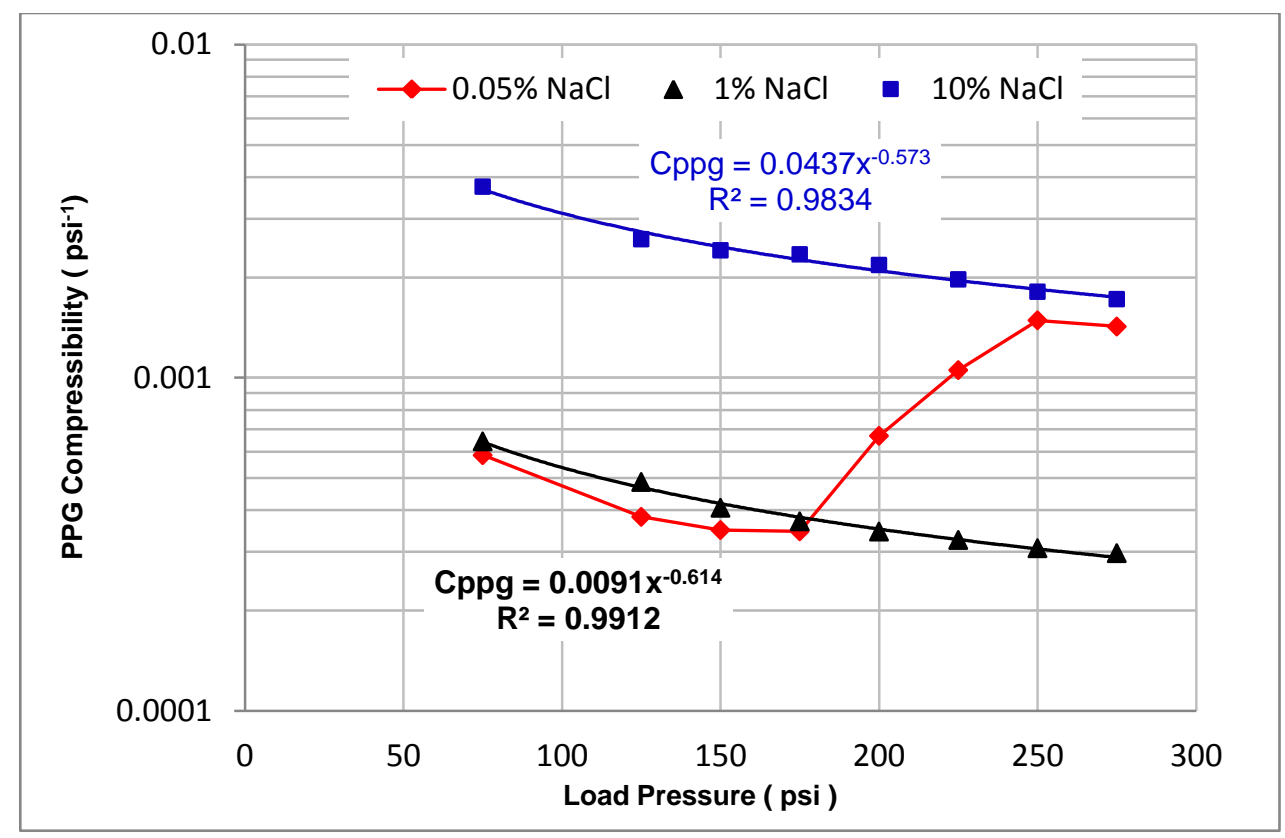

Fig. 8. Relationship between PPG compressibility (psi ${ }^{-1}$ ) and load pressure (psi).

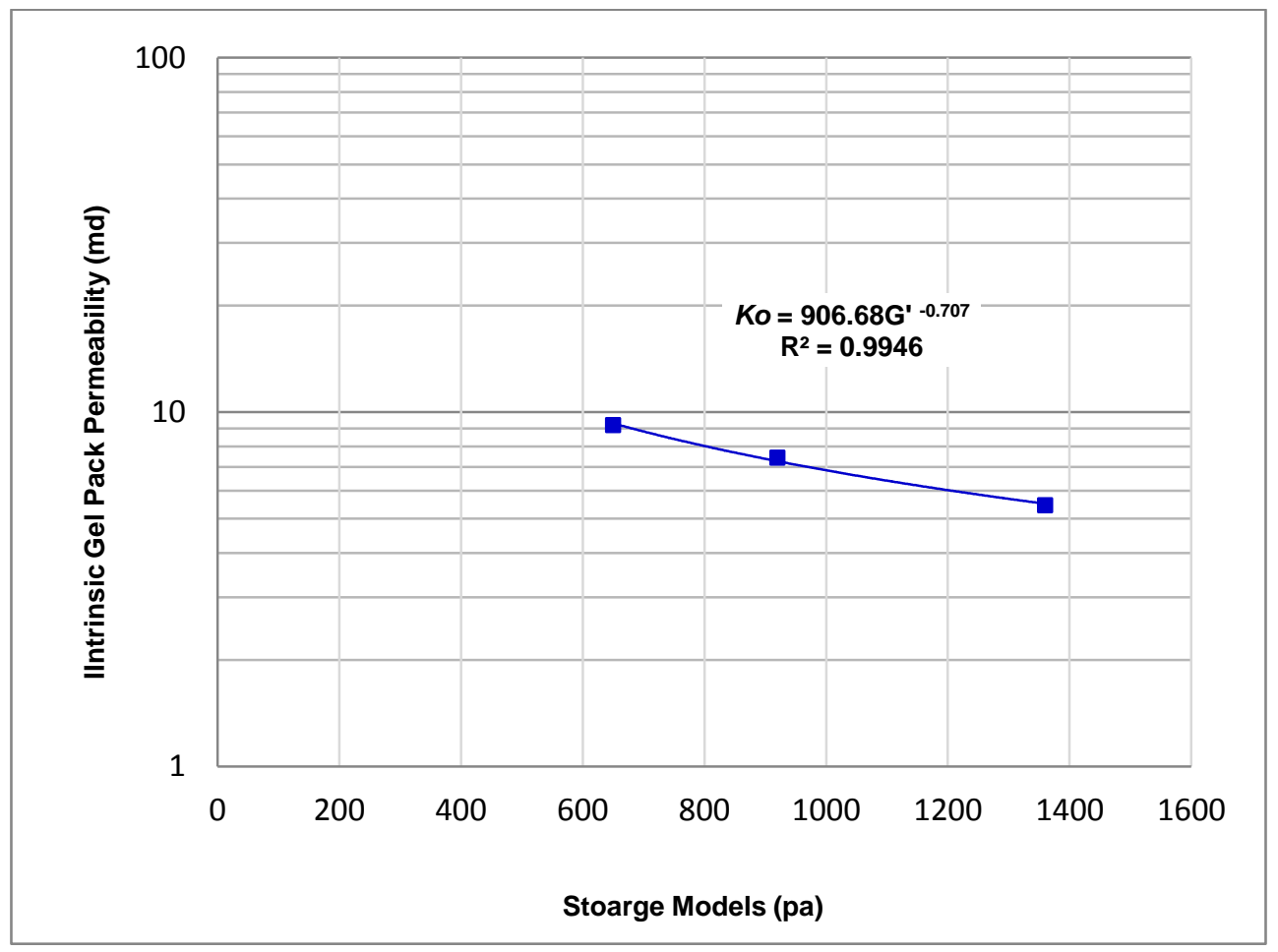

Fig. 9. Intrinsic gel pack permeability as a function of storage modulus. 